Journal of Social and Development Sciences

Vol. 4, No. 2, pp. 84-99, Feb 2013 (ISSN 2221-1152)

\title{
Technical Efficiency Analysis of Maize Farmers in the Eastern Region of Ghana
}

\author{
John K. M. Kuwornu*, Emmanuel Amoah, Wayo Seini \\ University of Ghana, Legon, Ghana \\ *jkuwornu@gmail.com
}

\begin{abstract}
This study assesses the technical efficiency and its determinants of maize farmers in the Eastern Region of Ghana. A multi stage random sampling procedure was employed to select 226 maize farmers from the four main geographical areas of the region for the study. A well-structured questionnaire and field observations were employed to collect relevant information from the respondents. Data collected was analyzed using relevant econometric techniques. The results indicate that elasticities of mean output for agrochemicals, hired labor, other inputs are positive while those of seed, fertilizer and family labor are negative. The computed return to scale on the other hand reveals that, on average, the maize farms exhibit decreasing returns to scale. The joint effect of operational and farm-specific factors influence technical efficiency but individual effects of some variables are not significant. Mean technical efficiency level of the farmers is estimated to be $51 \%$, indicating that the possibility of increasing maize production in the region given the current state of technology and inputs level can be achieved in the short run by increasing the technical efficiency level of the farmers by $49 \%$ through the adoption of practices of the best maize farmer. Further, the empirical results from the inefficiency model show that extension visit, FBO membership, frequency of meeting by members of FBOs, formal training in maize farming, cash and in-kind credits are the major determinants of the farmers' technical efficiency level. Finally, the resource use efficiency results revealed that agro-chemicals and hired labor are under-utilized whereas seed, fertilizer and family labor are over-utilized by maize farmers in the region. These results have implications for management of small and medium scale food crop farms in developing countries.
\end{abstract}

Keywords: Maize, Technical Efficiency, Resource Use Efficiency, Returns to scale, Ghana

\section{Introduction}

Agriculture sector contributes $25.6 \%$ to Ghana's GDP after the Services and Industrial sectors, and is the most important sector driving Ghana's economic growth. Agriculture accounts for the greatest proportion of Ghana's export earnings with principal Agricultural exports being cocoa, timber, horticultural products, fish/sea foods, game and wildlife. It is solely responsible for providing food security for both the rural and urban population. Agriculture supplies raw materials to feed industries and a major source of revenue yet Ghana's agriculture remains predominantly small scale and the majority of farmers are food crop farmers producing mainly for home consumption (MOFA, 2009 and GSS, 2012). Maize in particular is the first among the main crops contributing to Ghana's food security and also increases farmers' disposable income through their investment in its production in areas such as improved seeds, fertilizer and machinery use. As the production base becomes larger, the income again becomes incrementally larger and the farmers can lift themselves up to a far more commercial level and out of poverty. The farmer then spends a very small part of the income from maize on the household and therefore is able to improve his or her knowledge base. This all starts from the farmer receiving enough advice and exposure to the benefits of using improved inputs (WABS Consulting Ltd., 2008). However, in Ghana, the maximum yield obtained by staple crop farmers has been estimated to be $200 \%$ lower than the maximum attainable level (frontier) of their output whereas the minimum yield obtained by them is also estimated as $300 \%$ below the maximum attainable output level (Alhassan and Diao, 2007). Also, projected figures for household consumption depicts that there is considerable unfulfilled demand for processed maize for human uses and for the growing animal feed sector within Ghana (MoFA, 2010) so if policies are strengthened to improve trade in the sub region, maize could be exported to other countries within the sub Saharan region. Between 1979 and 1997, the government of Ghana and the Canadian government undertook a project which was aimed at improving maize with the objective of increasing maize yield, resistance to disease and pest, nutritional quality of maize and developing varieties to 
suit different agro-ecological zones in Ghana. The project developed and promoted the use of twelve improved varieties of maize, fertilizer recommendations and plant configurations. However, the impact of these recommendations has not been felt due to low performance of the cultivated varieties as a result of the physical environment, socioeconomic characteristics of the farmers and poor rural environment conditions (WABS Consulting Ltd., 2008). In the Eastern Region of Ghana, yield of maize from the farms ranges from 0.8 to 3.6 tons per hectare which are far below the maximum yield of 5.5 to 6 tons per hectare (Kwarteng and Towler, 1995; MoFA, 2006).

Thus, the maize productivity remaining low raises questions about the efficiency with which resources are used by farmers in Ghana even in periods when the country experiences favorable weather conditions. As noted by Abdulai and Teitje (2007) findings from the study of technical efficiency have far-reaching policy implications so the study of technical efficiency has drawn a lot of attention from researchers over the past 30 years in West Africa (Hallam and Machado, 1995). Despite the fact that Eastern Region ranks as the third largest maize producing region in the country, studies bordering on technical efficiency differentials in the region are scanty or none existing. For instance, WABS Consulting Limited (2008) and Al-Hassan et al., (2007) made some attempts but could not ascertain the differentials of technical efficiency of maize farms in the region. Also, even though these studies considered credit in their analysis, they mostly looked at the farmers' access to formal financial institutions' credit aspect only. They therefore did not to consider the individual effects of cash credit or in-kind credit use by farmers on technical efficiency. Therefore, there is the need for a study that will analyze the technical efficiency and its determinants for the four categories of farmers (Noncredit users, cash credit users, in-kind credit users and those farmers who use both cash credit and in-kind credit) in the region to provide the basis for the formulation of specific policies for boosting the efficiency of maize production in the study area based on the research findings. The objective of this study are four fold: To estimate the productivity of maize farms in the Region with respect to the input factors; estimate the technical efficiency level of maize farmers in the Region; examine the determinants of technical efficiency of maize crop farmers; and analyze the resources use efficiency of maize farms in the Region. The rest of the study is structured as follows. Section 2 provides the literature review, section 3 outlines the methodology employed; section 4 presents the empirical results; and section 5 provides the conclusions.

\section{Literature Review}

Production and Farm Efficiency: Case et al., (2009) defined efficiency as the condition in which the economy is producing what people want at least possible cost. Thus, the concept of efficiency is primarily concerned with the relative performance of the processes used in transforming given inputs into outputs. Economic theory propounded by Farrell (1957) identifies at least three types of efficiency. These are allocative, technical and economic efficiencies. Allocative efficiency refers to the choice of the best combination of inputs consistent with the relative factor prices. That is, allocative efficiency is the ability of a firm to use inputs in optimal proportions, given their respective prices. Technical efficiency shows the ability of firms to employ the 'best practice' in an industry, so that no more than the necessary amount of a given sets of inputs is used in producing the best level of output (Carlson, 1968). The product of technical and allocative efficiencies yields economic efficiency. The manager or the farmer is thus concerned with producing higher levels of output at the lowest possible cost. Therefore, the firms or farms make efforts to either reduce the cost of a certain level of output or to increase the output with a certain level of costs. These two optimization problems provide the same rule for the allocation of inputs and selection of technology. Because there are alternative means of achieving the production goals, the production theory gives the theoretical and empirical framework which helps in best selection among alternatives for anyone or a combination of the farmer's objectives to be achieved. Agricultural productivity is a measure of efficiency since the aggregate productivity of an economic system is proportional to the efficiency of production of the components within the systems (Olayide and Heady, 1982). Further, potential resource productivity means getting the maximum output from the minimum possible set of inputs. Thus, optimal productivity of resources demands an efficient usage of resources in the production process. Agricultural productivity can therefore be defined as a measure of efficiency with which the agricultural system utilizes land, labor, capital and other resources.

Technical Efficiency: Technical efficiency is defined as the physical ratio of product output to the factor inputs. The greater the ratio, the greater the size of the technical efficiency. This implies the existence of 
variation in technical efficiency among firms or farms. The production function pre-supposes technical efficiency, whereby maximum output is obtained from a given level of inputs combination; hence it is a factorproduct relationship. Generally, technical efficiency is the ability to minimize input use in the production of an output vector, or the ability to obtain maximum output from an input vector (Kumbhakar et al., 2000). An important assumption underlying efficiency concept is that firms operate on the outer bound of production function (i.e., on their efficiency frontier). Developments in cost and production frontiers are attempts to measure productive efficiency. The frontier defines the limit or boundary to a range of possible observed production (cost) levels and identifies the extent to which the firm lies below (above) the frontier (Farrell, 1957). It means that firms or farms become technically inefficient when they fail to operate on the outer bound of their production function. Such firms can improve their technical efficiency by three ways: (a) improved production techniques, which implies a change in factor proportions through factor substitution under a given technology, thus representing a change along the given production function; (b) an improvement in production technology, which represents a change in the production function itself in a way that the same amount of resources produce more output, or the same amount of output is derived from smaller quantities of resources than before, and (c) a simultaneous improvement in both production techniques and technology (Amaza et al., 2001). The technical efficiency of individual farmers according to Ogundari and Ojo (2007) refers to the ratio of observed output to the corresponding frontier's output, conditional on the level of input used by the farmers. Olayide and Heady (1982) however, defined technical efficiency as the ability of a firm to produce a given level of output with minimum quantity of inputs under a given technology. Efficiency can as such be seen as a vital determining factor of productivity growth of an individual farmer.

For efficient production, non-physical inputs, such as experience, information and supervision, might influence the ability of a producer to use the available technology efficiently. Each type of inefficiency is costly to a firm or production unit (e.g., a farm household) because it causes a reduction in profit below the maximum value attainable under full efficiency. Farell (1957) used an input-oriented scheme while Fare et al., (1985) employed an output-oriented scheme to measure efficiency. However, Coelli and Perelman (1996) showed that the choice of an orientation rarely has an influence on the reported efficiency scores. Parametric and non-parametric approaches are other common measuring tools of technical efficiency. Basically, nonparametric frontier technique has been fused into the Data Envelopment Analysis (DEA). Non-parametric frontiers do not impose a functional form on the production frontiers and do not make assumptions about the error term. These have used linear programming models to estimate firms' level of efficiency. Parametric frontier approaches impose a functional form on the production function and make assumptions about the data. The most common functional forms include the Cobb-Douglas, constant elasticity of substitution and translog production functions.

Cross-Sectional Production Frontier Models: Four methods are proposed for the estimation of Technical Efficiency (TE) using this type of data: Goal Programming, Corrected Ordinary Least Squares (COLS), Modified Ordinary Least Squares (MOLS), and Composed Error Model or Stochastic Production Frontier. We provide a brief description of each of these methodologies in turn as follows:

Goal Programming: with this method, the deterministic production frontier is converted to any of a pair of mathematical programming models. A linear programming model is used to calculate the parameter vectors as well as to minimize the sum of proportionate deviations of the observed output of each producer below the maximum feasible output. These results are then converted to measures of technical efficiency of the producers. Thus, $\min \sum_{i} u_{i}$, subject to $\left[\beta_{\mathrm{O}}+\sum_{n} \beta_{n} \ln x_{n i}\right] \geq \ln y_{i}, i=1, \ldots, I$.

The other model is a quadratic programming model which calculates the parameter vector $\beta$ and minimizes the sum of the squared proportionate deviations of the observed output of each producer. That is, $\min \sum_{i} u_{i}^{2}$, subject to $\left[\beta_{0}+\sum_{n} \beta_{n} \ln x_{n i}\right] \geq \ln y_{i}, i=1, \ldots, I$.

Technical efficiency is then calculated from the deviation as $T E_{i}=e\left\{-u_{i}\right\}$, where $u_{i}=\left[\beta_{0}+\sum_{n} \beta_{n} \ln x_{n i}\right]-\ln y_{i}, i=1, \ldots, I$ (Aigner and Chu, 1968). 
Since parameter vectors are not estimated using regression models, statistical inference about their values are complicated. The log likelihood estimates of these do not come with standard errors attached and also cannot be determined by traditional methods (Schmidt, 1976; Greene, 1980).

Corrected Ordinary Least Squares (COLS): OLS is used to estimate the parameter vectors and the intercept value concurrently. These estimated parameter vectors are consistent and unbiased but the estimated intercept is also consistent but biased. The biased intercept is corrected to make the estimated frontier bound the data from above (second step). That is $\hat{\beta}_{0}^{*}=\hat{\beta}_{0}+\max _{i}\left\{\hat{u}_{i}\right\} . \hat{U}_{i}$ are residuals of the OLS, which are corrected in the opposite direction. That is, $-\hat{u}_{i}^{*}=\hat{u}_{i}-\underset{i}{\max }\left\{\hat{u}_{i}\right\}$. Technical efficiency is estimated from the residuals as follows $T E_{i}=e\left\{-\hat{u}_{i}^{*}\right\}$. Even though this method is relatively simple and easy to use, the estimated variables in natural logs of the production are parallel to OLS regression. This means that the structure of the "best practice production technology" is the same as the structure of "central tendency production technology" yet the structure of the "best practice production technology" is expected to change from that of central tendency production technology down in the middle of the data where the other producers are less efficient than the best practice producers (Winsten, 1957).

Modified Ordinary Least Squares (MOLS): The deterministic production frontier model is estimated by OLS under assumption that the error term follows a one-sided distribution like exponential and half-normal distributions. The estimated intercept is then modified by the mean of the assumed one-sided distribution. That is, $\hat{\beta}_{0}^{* *}=\hat{\beta}_{0}+E(\hat{u})$ where $-\hat{u}_{i}^{* *}=\hat{u}_{i}-E\left\{\hat{u}_{i}\right\}$.

Technical efficiency is estimated in the same way as the COLS (Afrait, 1972; Richmond, 1974). This procedure is also simple and easy to implement but has it's limitations: it is possible to obtain a technical efficiency score greater than 1. MOLS also shifts $\beta_{0}$ so far that no producer is technically efficient and as well MOLS production frontier is parallel to OLS regression.

Composed Error Model or Stochastic Production Frontier: It assumes that $f\left(x_{i} ; \beta\right)$ takes log linear CobbDouglass form and so becomes $\ln y_{i}=\beta_{0}+\sum_{n} \beta_{n} \ln x_{n i}+v_{i}-u_{i}$ where $\mathrm{v}_{\mathrm{i}}$ is the two sided noise component and $u_{i}$ is the nonnegative technical inefficiency component of the error term. $v_{i}$ is assumed to be $\sim \mathrm{N}\left(0, \boldsymbol{\sigma}^{2} \mathrm{v}\right)$ (i.e. it has a technical inefficiency modal value of zero) and symmetric, distributed independently of $u_{i}$ and $u_{i}$ assumed to be $\sim \mathrm{N}^{+}\left(0, \boldsymbol{\sigma}^{2} \mathrm{u}\right)$ (i.e. it has technical inefficiency modal value of zero with less likely increasing technical inefficiency values). Thereafter, technical efficiency was defined as the ratio of observed output to maximum feasible output in an environment characterized by $\exp \left\{v_{i}\right\}$. Thus, $T E_{i}=\frac{\mathrm{y}_{i}}{f\left(x_{i} ; \beta\right) \cdot \exp \left\{v_{i}\right\}}$, where the denominator on the right hand side is the stochastic frontier consisting of the deterministic part that is common to all producers and $\exp \left\{v_{i}\right\}$ which is the producer-specific portion capturing effects of random shocks on each producer. The stochastic frontier method would be employed in this study because it makes it possible to determine the efficiency levels for policy formulation purposes as well as being useful for identifying the sources of the inefficiencies in the system. The single step estimation approach proposed by (Coelli, 1995) would be used to compute the relationship between the farm/farmer characteristics and the technical efficiency index:

$Y_{i}=f\left(x_{i} ; \beta\right) e^{v_{i}-u_{i}}$

Where, $Y_{i}$ is output, $x_{i}$ a vector of inputs, $\beta$ a vector of parameters to be estimated and $e$ represent exponent. The error $\mathrm{v}_{i}$ is $\sim \mathrm{N}\left(0, \sigma_{\mathrm{v}}{ }^{2}\right)$ and captures random variation in output due to the factors beyond the control of 
the farmers, such as variation in weather, measurement error and other statistical noise. The error term $u_{i}$ captures technical inefficiency in production, assumed to be farm-specific with non-negative random variables, $\sim \mathrm{N}^{+}\left(\mu_{\mathrm{i}}, \sigma_{\mathrm{u}}^{2}\right)$. This means that the $u_{i}$ is distributed as truncation (i.e. at zero) of the normal distribution with mean, $\mu_{\mathrm{i}}$, and variance $\sigma_{\mathrm{u}}{ }^{2}$. The $\mu_{\mathrm{i}}$ (mean) is defined as:

$\mu_{i}=Z_{i} \theta$

where, $Z_{\mathrm{i}}$ is a $(\mathrm{P} \times 1)$ vector of independent variables associated with the technical inefficiency effects which could capture socio-economic farm management features. $\mathrm{P}$ is a $(1 \times \mathrm{P})$ vector of unknown parameter to be estimated. A higher value for $u_{i}$ implies an increase in technical inefficiency. If $u_{i}$ is zero, the farm is perfectly technically efficient. This implies the boundary of the production defined by the "best practice" farm. Thus, it indicates the maximum potential output for a given set of inputs, $x_{i}$. The maximum potential output is given as follows;

$Y_{i}^{*}=f\left(x_{i} ; \beta\right) e^{v_{i}}$

Technical efficiency can thus be measured as:

$T E_{i}=\frac{f\left(x_{i} ; \beta\right) e^{v_{i}-u_{i}}}{f\left(x_{i} ; \beta\right) e^{v_{i}}}=e^{-u_{i}}$

The difference between the maximum potential output and the actual output is embodied in the $u$. If $u_{i}=0$ then $\frac{Y_{i}}{Y_{i}^{*}}$ production lies on the frontier and hence technically efficient, but if $u_{i}>0$ then production lies below the frontier and the farm is said to be inefficient (Battese and Coelli, 1995).

Estimation Procedure for the Stochastic Frontier Function: The stochastic frontier model involves estimating the parameters first and then the estimation of the technical efficiency follows. The estimation methods must follow the assumptions underlying the noise error term $\left(v_{i}\right)$ as stated above and the inefficiency error term. The inefficiency component represents a variety of features that reflect inefficiency such as farm-specific knowledge; the will, skills, and effort of management and employees; work stoppages, material difficulties, and other disruptions to production (Aigner et al., 1977; Lee and Tyler, 1978; Page, 1980). Meeusen and van den Broeck (1977) and Aigner et al., (1977) assume that $u_{i}$ has an exponential and a half-normal distribution, respectively. Both distributions have a mode of zero. Other proposed specifications of the distribution of $u_{i}$ include a truncated normal distribution $\sim N\left(\mu, \sigma^{2}\right)$ (Stevenson, 1980) and the gamma density (Greene, 1980). This study employs the model developed by Battese and Coelli (1995) which assumes that $u_{i}$ is normally distributed with mean zero and a constant variance [i.e. $\left.\sim \mathrm{N}^{+}\left(0, \sigma_{\mathrm{u}}{ }^{2}\right)\right]$. It is significant to separate the composed error term for efficiency measurement. That is,

$\varepsilon_{i}=\left(v_{i}-u_{i}\right)$. If $u_{i}=0$, then, $E\left(u_{i} \mid \varepsilon_{i}\right)$ is the expected value of $u_{i}$ conditioned on the error term (Jondrow et al., 1982). When the conditional estimate of $u_{i}$ is obtained, then the technical efficiency level of an individual farmer is estimated as $T E_{i}=e\left\{E\left(u_{i} \mid \varepsilon_{i}\right)\right\}$. The correct estimator $T E_{i}=E\left(e\left\{-u_{i}\right\} \mid \varepsilon_{i}\right)$ is the formula employed in this research (Coelli, 1995). Depending on the assumption of the random errors, the maximum likelihood single stage estimation procedure for estimating the parameters of the frontier model, inefficiency model and the farm-specific $\mathrm{TE}_{i}$ defined by the measure of efficiency of technical efficiency model are 
obtained by the parameterization: $\sigma^{2}=\sigma_{\mathrm{v}}{ }^{2}+\sigma_{\mathrm{u}}{ }^{2}$ and $\gamma=\sigma_{\mathrm{u}}{ }^{2} / \sigma^{2}=\sigma_{\mathrm{u}}{ }^{2} /\left(\sigma_{\mathrm{v}}{ }^{2}+{\sigma_{\mathrm{u}}}^{2}\right)$ (Battese and Corra, 1977), where $\sigma^{2}=$ total variation, $\sigma_{\mathrm{v}}{ }^{2}=$ variation resulting from noise, $\sigma_{\mathrm{u}}{ }^{2}=$ variation arising from inefficiency and $\gamma=$ 1 implies variance from the frontier is wholly due to inefficiency while $\gamma=0$ implies variance from the frontier totally comes from noise effects. That is, for $0<\gamma<1$, output variation is attributed to both stochastic errors and technical inefficiency.

\section{Methodology}

The Study Area: The Eastern region of Ghana is made up of 21 districts that has been categorized into four main geographical areas: the Kwahu scarp that has an elevation of 2,586 feet above sea level; the AtiwaAtwaredu Ranges near Kibi with an elevation of 2,400 feet; the Akuapem highland which has an elevation of 1,530 feet and is the continuation of the southern portion of the Togo-Atakora mountain ranges; and the isolated hills or mountains dotting the relatively low-lying plains to the south. The Krobo and the Yogaga mountains are the prominent ones among these hills or mountains (http//www."Eastern Region"GhanaNation.com (accessed 11 thDecember, 2010). The forest and savannah type of soils are suitable for the cultivation of different kinds of crops such as cocoa, cola-nuts, citrus, oil palm and staple food crops such as cassava, yam, cocoyam, maize, rice and vegetables. Some exotic crops like black and sweet pepper, ginger, cashew nuts, Irish potatoes, rubber and mangoes also thrive well in the region. These exotic crops are also gaining importance as export commodities (http//www."Eastern Region"GhanaNation.com). The region lies within the wet semi-equatorial zone which has a double maxima rainfall that occurs in June and October. The first rainy season starts from May and ends in July, with the heaviest rainfall occurring in June. The second rainy season starts from September and ends in November. However, there are variations in the distribution of this bimodal rainfall among the districts. Temperatures in the region are high and range between $26^{\circ} \mathrm{C}$ and $30^{\circ} \mathrm{C}$. The relative humidity is also high throughout the year and varies between $70-80 \%$ (http//www"Eastern Region"GhanaNation.com (accessed 11 th December, 2010).

Type and Sources of Data: A well-structured questionnaire was administered in 2010 to obtain the relevant primary qualitative and quantitative data from 226 maize farmers in the Eastern Region of Ghana. The Secondary data sources were from research offices of agriculture, MiDA statistical department, Ghana Statistical Service, text books, on-line materials and published Agricultural Journals which assisted us to check the reliability, conformity and consistency of the results obtained from the study.

Sampling Method and Sample Size: A multistage sampling technique was used to select 226 respondent farmers. Thus, purposive sampling technique was employed to select the Eastern Region from the 10 regions of the country as well as the five districts; then simple random sampling procedure was employed to select 63 communities from which the 226 maize farmers were selected using the same procedure.

Methods of Analysis, Translog Production: As the first step in the estimation procedure of technical efficiency of a production process, the computer software, Frontier Version 4.1 was employed to estimate the coefficients of the inputs variables using the translog functional form. The function is expressed as:

$\ln Y_{q}=\beta_{0}+\sum_{p=1}^{6} \beta_{p} \ln x_{p q}+0.5 \sum_{p=1}^{6} \sum_{r=1}^{6} \beta_{p r} \ln x_{p q} \ln x_{r q}+\left(v_{q}-u_{q}\right)$

Where, $Y$ is the total quantity or volume of maize produced, $\ln =$ natural logarithm, $q=q$ th maize farmer for $q$ $=1,2,3 \ldots 226, x_{p q}=$ amount of input $p$ used by $q$-th maize farmer with an assumption that there is symmetry in input cross effects by considering $\beta_{p r}=\beta_{r p}$ but if $\beta_{p r}=0$ then the translog stochastic frontier model will be reduced to the Cobb Douglas Production Function. Where, $x_{1}=\operatorname{seed}(\mathrm{kg}) / \mathrm{Ha} ; x_{2}=$ fertilizer $(\mathrm{kg}) / \mathrm{Ha}$; 
$x_{3}=$ agro-chemicals $(\mathrm{kg} / \mathrm{Ha}$ or $\mathrm{L} / \mathrm{Ha}) ; x_{4}=$ other inputs $(\mathrm{GHd})^{1} ; x_{5}=$ family labor (man-days) $/ \mathrm{Ha} ; x_{6}=$ hired labor (man-days)/Ha; $\beta_{q}=$ parameter to be estimated; $v_{q}=$ random errors from the stochastic frontier production and $u_{q}=$ a vector of non-negative technical inefficiency component of the error term. Mention

Elasticities: According to Onumah et al. (2010), the estimated parameters $\beta_{1}, \beta_{2} \ldots \beta_{6}$ are output elasticities of the corresponding inputs in the Cobb-Douglas stochastic frontier production function (6). However, the elasticities of output based on different inputs are functions of the level of inputs employed in the translog stochastic production function.

It is expressed as:

$$
\frac{\partial \ln E\left(Y_{p}\right)}{\partial \ln x_{p q}}=\beta_{p}+\beta_{p} \ln x_{p q}+\sum_{r \neq p} \ln x_{r q}
$$

Moreover, when the output and input variables have been normalized by their respective sample means, the first order coefficient can be interpreted as elasticities of output in relation to the different inputs. The summation of the output elasticities is the estimated scale elasticity $(\varepsilon)$. It is defined as the percentage change in output from $1 \%$ change in all input factors. It is a measure of returns to scale for a farm or industry.

\section{Returns to scale decision rule}

$(\varepsilon) \succ 1$ implies increasing returns to scale (IRS)

$(\varepsilon) \prec 1$ implies decreasing returns to scale (DRS)

$(\varepsilon)=1$ implies constant returns to scale (CRS).

Estimating the technical efficiency level of the maize farmers: Using an output orientation of the frontier, the farmers' maize production frontier was formulated as a stochastic maize production frontier in a crosssectional context following: $\mathrm{y}_{q}=f\left(x_{i} ; \beta\right) \times \mathrm{e}^{v_{q}} \times T E_{q}$ where, $f\left(x_{q} ; \beta\right) \mathrm{e}^{v_{q}}$ is the stochastic production frontier consisting of the deterministic part $f\left(x_{q} ; \beta\right)$ common to all maize producers in the sample and a producer-specific part $\mathrm{e}^{\left(v_{q}\right)}$ capturing the effects of random shocks on each individual maize farmer. Technical efficiency is then simply defined by $T E_{q}=\frac{\mathrm{y}_{q}}{f\left(x_{i} ; \beta\right) \mathrm{e}^{\mathrm{v}_{q}}}$ i.e. the ratio of observed maize output to maximum feasible maize output in an environment characterized by $\mathrm{e}^{\left(v_{q}\right)}$ (Tchale and Sauer, 2007). The onestep maximum likelihood estimation procedure developed by Coelli (1995) was used to estimate the technical efficiency level of the farmers after the estimation of the input parameters. This was accomplished by first estimating the expected value of the $u_{q}$ conditioned on the error term (i.e. $E\left\{u_{q} \mid \varepsilon_{q}\right\}$ ) as proposed by Jondrow et al., (1982). The next step was the determination of the technical efficiency level of the individual farmers which was done by the use of the Frontier Version 4.1 software. The model employed was $T E_{q}=E\left(e\left\{-u_{q}\right\} \mid \varepsilon_{q}\right)$. The final step was the estimation of the mean technical efficiency level of the maize farmers in the study area which was also carried out by the use of the same Frontier Version 4.1 software. The meanings of the variables in the models as well as the assumptions underlying them are the same as explained in the estimation procedure.

Examining the determinants of technical efficiency of maize crop farmers: The various farm-specific variables hypothesized to influence technical inefficiencies in maize farms in the region are defined by the model:

\footnotetext{
${ }^{1}$ Please note that the farmer's use of other inputs (aside the inputs stated above), would lead to "other costs".
} 
$\mu_{p q}=\theta_{0}+\sum_{p=1}^{16} \theta_{p} z_{p q}$

Where, $\mu_{p q}$ represents the technical efficiency of the $q$-th farmer; $\mathrm{Z}_{1}=$ Akuapem North district; $\mathrm{Z}_{2}=$ Birem South district; $Z_{3}=K w a h u$ North district; $Z_{4}=$ Upper Manya Krobo district; $Z_{5}=$ farm experience (years); $Z_{6}=$ educational level (years); $Z_{7}=$ extension visits (number); $Z_{8}=$ household size (number); $Z_{9}=$ gender ; $Z_{10}=$ FBO membership; $\mathrm{Z}_{11}=$ off-maize farm work ; $\mathrm{Z}_{12}$ = formal training in maize farming; $\mathrm{Z}_{13}=$ cash credit (GH 4 ); $\mathrm{Z}_{14}=$ in-kind credit $(\mathrm{GH}) ; \mathrm{Z}_{15}=$ both cash and in-kind credit $(\mathrm{GH} \Phi) ;$ and $\mathrm{Z}_{16}=$ frequency of farmers' groups meeting (number). The maximum-likelihood estimates of the $\beta$ and $\theta$ coefficients in equations (5) and (7) was estimated simultaneously by the use of Frontier Version 4.1 software.

Statement of hypotheses : These hypothesis will be tested using the generalized likelihood ratio test that is calculated using the formula: $L R=-2\left\{\ln \left(\frac{L W}{L U}\right)\right\}=-2\{\ln (L W-L U)\}$, where $\ln (\mathrm{LW})$ is the value of the log likelihood function for the restricted stochastic frontier model and $\ln (\mathrm{LU})$ being the value of $\log$ likelihood functions for the unrestricted stochastic frontier model. The LR is assumed to be mixed chi-square distributed.

1. Ho: $\beta_{j k}=0$, coefficients of the second order variables are zero which implies that the Cobb Douglas function statistically best fit the data.

2.

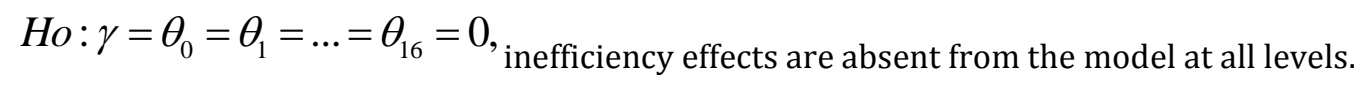

3. Ho: $\gamma=0$, inefficiency effects are non-stochastic. Thus, stochastic frontier model minimizes to the original average response function in which the $z_{q}{ }^{\prime} s$ in the technical inefficiency model are couched in the production function.

4. Ho: $\theta_{0}=\theta_{1}=\ldots=\theta_{16}=0$, simpler half normal distribution is an adequate representation of the data.

5. Ho: $\theta_{1}=\theta_{2}=\ldots=\theta_{16}=0$, farm specific factors do not influence the inefficiencies.

6. Ho: $\theta_{13}=\theta_{14}=\theta_{15}=0$, no effects of credit on technical efficiency.

7. Ho: $\theta_{1}=\theta_{2}=\ldots=\theta_{4}=0$, no effects of district variations on technical efficiency of the farmers.

Analyzing the resource use efficiency by the farmers in the Region: The resource use efficiency was realized from the estimated equation (5) by comparing the Marginal Value Product (MVP) of an input with the Marginal Factor Cost (MFC) of that input. The MVP of each input was calculated using the equation $\operatorname{MVPx}_{p}=\frac{\partial y}{\partial x_{p}} * p y$, where, $\frac{\partial y}{\partial x_{p}}$ is the Marginal Physical Product of $x_{p}\left(M P P x_{p}\right)$ and $p y$ is the unit price of the output (Y). Following suit, the MFC was calculated by the use of the equation $M F C x_{p}=\frac{\partial y}{\partial x_{p}} * p x$, where $p x$ is the unit price of input $x_{p}$ (see for example, Kolawole, 2010 for exposition).

\section{Resource use efficiency decision rule}

If $M V P x_{p}>M F C x_{p}$, there is under- utilization of resource $x_{p}$.

If $M V P x_{p}<M F C x_{p}$, there is over- utilization of resource $x_{p}$.

If $M V P x_{p}=M F C x_{p}$, there is optimum utilization of resource $x_{p}$. 


\section{Results}

Summary Statistics of Variables Used for this Study: The mean output realized by the farmers was $2386.99 \mathrm{Kg} / \mathrm{Ha}$. This was achieved by utilizing on average, $20.50 \mathrm{Kg} / \mathrm{Ha}$ of seed, $145.89 \mathrm{Kg} / \mathrm{Ha}$ of fertilizer, $6.35 \mathrm{Kg} / \mathrm{H}$ or L/Ha of agro-chemicals, GH\$ 101.82/Ha of other inputs, 301.09 man-days/Ha of family labor and 162.91man-days/Ha of hired labor (see Table 1).

Table 1: Statistics of variables in the stochastic production frontier function

\begin{tabular}{llllll}
\hline Variable & Unit & Minimum & Maximum & Mean & Standard Deviation \\
\hline Output & $\mathrm{Kg} / \mathrm{Ha}$ & 461.16 & 7280.00 & 2386.99 & 1353.29 \\
Seed & $\mathrm{Kg} / \mathrm{Ha}$ & 3.00 & 56.25 & 20.50 & 7.92 \\
Fertilizer & $\mathrm{Kg} / \mathrm{Ha}$ & 1.00 & 601.00 & 145.89 & 138.98 \\
Agro-chemicals & $\mathrm{Kg}$ or L/Ha & 1.00 & 23.50 & 6.35 & 3.82 \\
Other inputs & $\mathrm{GH}$ /Ha & 1.50 & 437.50 & 101.82 & 70.94 \\
Family labor & Man-days/Ha & 1.00 & 1714.00 & 301.09 & 326.04 \\
Hired labor & Man-days/Ha & 1.00 & 2139.50 & 162.91 & 303.07 \\
\hline
\end{tabular}

The age of the respondents ranges from 22 to 84 years with the mean age being 44 years. The mean farm experience of 20.09 years suggests that the farmers have gained enough and better managerial skills. Further, $23.9 \%$ and $76.1 \%$ of the farmers interviewed were females and males respectively. Meanwhile, $68.6 \%$ of the respondents were members of FBOs while $31.4 \%$ of them were not members of any FBO in the study area. Also, $84.1 \%$ of the farmers engaged themselves in other works such as: other food crop production, cash crop production, artisanship, petty- trading in addition to their maize production, whereas only $15.9 \%$ cultivated maize alone (see Table 2).

Table 2: Statistics of Socio-economic Characteristics of the Respondents

\begin{tabular}{lllll}
\hline Variable & Minimum & Maximum & Mean & Standard Deviation \\
\hline Age & 22 & 84 & 44 & 10.21 \\
Farm experience & 2.00 & 50.00 & 20.09 & 9.51 \\
Education & 0.00 & 7.00 & 1.81 & 1.11 \\
Extension visits & 0.00 & 30.00 & 9.98 & 7.83 \\
Household size & 1.00 & 22.00 & 6.88 & 3.10 \\
Cash credit & 55.00 & 6400.00 & 1040.39 & 1067.11 \\
In-kind credit & 5.00 & 877.50 & 320.31 & 204.78 \\
Both cash and in-kind credit & 130.0 & 3225.00 & 823.61 & 578.59 \\
\hline
\end{tabular}

Diagnostic Statistics: The diagnostics statistics are presented in Table 3 below. The translog stochastic frontier production function specification best fit the data as the Cobb-Douglas function was rejected. There is presence of inefficiency effects in the model that are stochastic. In addition, the assumption that technical inefficiency effects have a half-normal distribution with mean of zero is rejected meaning that the assumption truncated normal distribution employed by the Frontier Version 4.1 software is adequate for the data. Moreover, the hypothesis which states that farm specific factors do not influence the inefficiencies is also rejected strongly. These results demonstrate that the combined effects of variables in the technical inefficiency model are crucial in explaining the variation in production of maize farms in the Eastern Region of Ghana. Finally, the rejection of both hypotheses six and seven reveal that credit and district variability significantly influence maize production in the study area. Again, the estimate of $\gamma$ is 0.999 suggests that about $99.9 \%$ of the variation in output among the farmers is due to the differences in technical efficiency, and that only $0.01 \%$ of the variation in maize output among the farmers is caused by random shocks outside the farmers' control.

${ }^{2}$ Please note that the unit of measurement for powered type of agro-chemicals is kilograms (Kg), and that of liquid type agro-chemicals is liters (L) 
Table 3: Validation of Hypotheses

\begin{tabular}{lllll}
\hline Null hypothesis & $\begin{array}{l}\text { Log-likelihood } \\
\text { value }\end{array}$ & $\begin{array}{c}\text { Test } \\
\text { statistics }(\lambda)\end{array}$ & $\begin{array}{l}\text { Critical value } \\
\left(\lambda^{2} \mathbf{0 . 0 5}\right)\end{array}$ & Decision \\
\hline Ho: $\beta_{j k}=0$ & -76.34 & 40.46 & 32.671 & Reject Ho \\
$H o: \gamma=\theta_{0}=\theta_{1}=\ldots=\theta_{16}=0$ & 118.60 & 118.60 & 28.268 & Reject Ho \\
Ho $: \gamma=0$ & 118.60 & 118.60 & 2.706 & Reject Ho \\
Ho: $: \theta_{0}=\theta_{1}=\ldots=\theta_{16}=0$ & -115.16 & 118.10 & 27.587 & Reject Ho \\
Ho $: \theta_{1}=\theta_{2}=\ldots=\theta_{16}=0$ & -115.54 & 118.86 & 26.296 & Reject Ho \\
Ho: $: \theta_{13}=\theta_{14}=\theta_{15}=0$ & -76.29 & 40.36 & 7.815 & Reject Ho \\
Ho: $: \theta_{1}=\theta_{2}=\ldots=\theta_{4}=0$ & -72.71 & 33.20 & 9.488 & Reject Ho \\
\hline
\end{tabular}

The Maximum Likelihood Estimates: The maximum likelihood estimates are presented in Table 4 below. Out of the six variables in the translog stochastic frontier model, three were found to be statistically significant. These are agro-chemicals, other inputs and hired labour. Agro-chemicals in the form of pesticides, fungicides and weedicides among others impacted positively on the output of maize. This shows that application of these chemicals will protect the maize from the destruction of pests, insects and fungi among others. Activities of these organisms on crops such as maize lead to lower levels of output as they can destroy large size of farm crops. This result are consistent with Kwarteng and Towler (1995) who contend that weeds and fungi attacks on maize plant reduce its ability to photosynthesize leading to drastic yield reduction. The coefficient of hired labour indicates that maize output will rise by $0.14 \%$ if hired labour use is increased by $1 \%$. This implies that if a maize farmer has money for additional labour, he/she can increase the size of his/her farm leading to the expansion of output. This is because food crop production such as maize is labour intensive and therefore will require more labour especially for weeding and harvesting operations. This result is also consistent with Amaza et al., (2001) who reveal that farmers who had the main objective of income maximization in food crop production will tend to allocate hired labour more efficiently. The other costs which refer to the cost of ploughing the land, transaction cost (in the form of phone calls and transportation) and the cost of capital items such as hoes, cutlass and spraying machine was significant at $10 \%$. Its coefficient shows that an increase in the use of other inputs by $1 \%$ will lead to $0.1 \%$ increase in maize output. These findings confirm those of (Gbigbi, 2011; Kibaara, 2005; Barnes, 2008).

Productivity Analysis: For a production process within which all resources vary in the same proportion, the summation of the partial elasticity of production with regards to each input stands for returns to scale or total output elasticity (a measure of productivity). This was estimated to be 0.47 for maize production in the Eastern Region of Ghana implying a decreasing return to scale. That is, if the maize farmers in the region increase all resources by $1 \%$, maize output also rise by $0.47 \%$. This estimate is consistent with Gbigbi (2011) who also obtained a value of 0.86 , but contrary to Essilfie et al. (2011) who obtained a value of 1.49 depicting increasing returns to scale.

Technical Efficiency of Maize Farmers: The Technical Efficiency of Maize Farmers is presented Table 5. The predicted technical efficiencies vary greatly among the maize farmers in the region. The results reveal that $32.3 \%$ of the farmers have technical efficiency ranging from 21 to $40 \%$, followed by $16.8 \%$ of them also getting efficiency range between 41 to $50 \%$. Further, the results show that few of the farmers (19\%) operated between 71 to $100 \%$ efficiency levels. Additionally, the results indicate that majority of farmers (about 55\%) are producing maize on a lower level of efficiency while only $6.2 \%$ among them are either producing on the frontier or closely to the frontier. These results are consistent with Essilfie et al. (2011) who reveal that only $12.1 \%$ of maize farmers in the Central Region of Ghana have technical efficiency of above 0.8 . The predicted mean technical efficiency of the farmers is 0.51 in the 2010 production year in the region. This indicates that the maize farmers in the study area produced $51 \%$ of the potential stochastic frontier output based on the present state of technology as well as the level of input. The implication is that the $49 \%$ of potential output is 
not realized. Possibly, the adoption of the practice of the "best farm" will increase maize production in the region by an average of $49 \%$ to enable these maize farmers to attain the potential stochastic frontier output level.

Technical Inefficiency Model Estimates: The positive coefficients of the Akuapen North, Kwahu North and Birem South districts bring to light that maize farmers in these districts are far less technically efficient compared to those maize farmers in Fanteakwa district and vice versa. This finding is consistent with that of Onoja et al., (2008) who ascribed variations among zones (in this case, the districts) to either the differences in farm management practices or heterogeneous nature of edaphic and climatic factors. Interestingly, the estimated coefficient for extension visit is positive. This leads to the implication that either extension agents did not offer enough productive advice to the farmers or the farmers are conservative and therefore did not imbibe and apply innovations of farm management practices taught them, and that increments of this sort of contacts will raise the farmers' inefficiency in maize production. There is a disagreement between this finding and earlier studies such as Msuya et al., (2008) yet consistent with Chirwa (2007) and Essilfie et al., (2011). A surprising result worth noting is that of FBO membership has positive coefficient. This suggests that farmers who are members of farmer-based organizations are less technically efficient than their counterparts who are not members of any farmer based group in maize production. This occurrence may be as a result of members in their respective groups spending so much time in planning and bargaining for inputs acquisition from government and non-governmental institutions, higher producer prices and favourable market outlets at the expense of them learning enhanced agronomic practices during their meetings. The estimated coefficient for their frequency of meeting indicates that the one month interval for the farmers meeting ensures that issues raised and ideas shared in previous meetings are constantly fresh in the farmers' minds.

Applications of these ideas to their maize farming technology augment the efficiency at which they produce maize than their colleagues who due to the long intervals between their meetings forget ideas shared among them. The impact of training farmers formally on improved ways of cultivating maize is very paramount as shown by the $10 \%$ significant level of the coefficient estimate (Table 6). The coefficient estimate of -0.154 reveals that farmers who were taught scientific ways of cultivating maize from at least the Junior Secondary School level minimize their level of production inefficiency by $15.4 \%$. This is because the formal training offers them the opportunity to search for and apply innovations in crop farming as well as increasing their technical know-how in maize cultivation among others. The least is the estimated coefficients for cash credit, in-kind credit and those farmers using both types of credit which are significant at $1 \%$ level respectively (see Table 6). These estimates imply that the famers who use cash credit, in-kind credit or both in maize production reduce their technical inefficiency levels by $42.9 \%, 70.1 \%$ and $60.5 \%$ respectively. These results are consistent with a number of research findings as follows: Ahmad et al., (2006) found that in-kind input credit in the form of fertilizer and seed increase crop output massively; Waqar et al., (2008) also revealed that institutional credit (cash credit), seed, fertilizers and irrigation significantly boost agricultural production; Olagunju (2007) showed that the farmers with credit are resourcefully efficient than their counterparts producing without credit; and Binam et al., (2004) revealed that access to credit permits a farmer to improve efficiency by overcoming liquidity constraints which may affect their ability to apply inputs and implement farm management decisions on time.

Table 4: Maximum Likelihood Estimates for the parameters of the stochastic frontier model

\begin{tabular}{|c|c|c|c|c|}
\hline Variable & Parameters & Coefficient & Standard error & t-value \\
\hline Constant & $\beta_{0}$ & $0.936^{* * *}$ & 0.051 & 18.283 \\
\hline LnSeed & $\beta_{1}$ & -0.0006 & 0.136 & -0.005 \\
\hline LnFertilizer & $\beta_{2}$ & -0.065 & 0.061 & -1.073 \\
\hline LnAgrochemicals & $\beta_{3}$ & $0.309^{* * *}$ & 0.028 & 10.901 \\
\hline LnOtherinputs & $\beta_{4}$ & $0.099^{*}$ & 0.055 & 1.807 \\
\hline LnFamilylabour & $\beta_{5}$ & -0.009 & 0.039 & -0.22 \\
\hline LnHiredlabour & $\beta_{6}$ & $0.143^{* * *}$ & 0.018 & 7.826 \\
\hline $0.5(\text { Lnseed })^{2}$ & $\beta_{7}$ & $-0.300^{*}$ & 0.177 & -1.695 \\
\hline
\end{tabular}




\begin{tabular}{|c|c|c|c|c|}
\hline 0.5 (Lnfertilizer) $^{2}$ & $\beta_{8}$ & $-0.050^{*}$ & 0.028 & -1.813 \\
\hline 0.5 (LnAgrochemicals) $^{2}$ & $\beta_{9}$ & $0.292^{* * *}$ & 0.041 & 7.111 \\
\hline 0.5 (LnOtherinputs) $^{2}$ & $\beta_{10}$ & -0.0513 & 0.0807 & -0.635 \\
\hline 0.5 (LnFamilylabour $)^{2}$ & $\beta_{11}$ & -0.008 & 0.017 & -0.469 \\
\hline $0.5{\text { (LnHiredlabour })^{2}}^{2}$ & $\beta_{12}$ & $0.048^{* * *}$ & 0.012 & 4.039 \\
\hline LnSeed.LnFertilzer & $\beta_{13}$ & -0.017 & 0.039 & -0.425 \\
\hline LnSeed.LnAgrochemicals & $\beta_{14}$ & -0.124 & 0.112 & -1.11 \\
\hline LnSeed.InOtherinputs & $\beta_{15}$ & 0.04 & 0.117 & 0.344 \\
\hline LnSeed.LnFamilylabour & $\beta_{16}$ & -0.024 & 0.035 & -0.675 \\
\hline LnSeed.LnHiredlabour & $\beta_{17}$ & 0.032 & 0.041 & 0.783 \\
\hline LnFertilizer.LnAgrochemicals & $\beta_{18}$ & -0.013 & 0.013 & -0.953 \\
\hline LnFertilizer.LnOtherinputs & $\beta_{19}$ & -0.011 & 0.018 & -0.61 \\
\hline LnFertilizer.LnFamilylabour & $\beta_{20}$ & 0.007 & 0.009 & 0.79 \\
\hline LnFertilizer.LnHiredlabour & $\beta_{21}$ & $0.012^{* *}$ & 0.006 & 1.984 \\
\hline LnAgrochemicals.LnOtherinputs & $\beta_{22}$ & $0.111^{* * *}$ & 0.035 & 3.212 \\
\hline LnAgrochemicals.LnFamilylabour & $\beta_{23}$ & 0.009 & 0.024 & 0.388 \\
\hline LnAgrochemicals.LnHiredlabour & $\beta_{24}$ & -0.021 & 0.023 & -0.913 \\
\hline LnOthercosts.LnFamilylabour & $\beta_{25}$ & 0.019 & 0.034 & 0.56 \\
\hline LnOThercosts.LnHiredlabour & $\beta_{26}$ & 0.013 & 0.015 & 0.516 \\
\hline LnFamilylabour.LnHiredlabour & $\beta_{27}$ & -0.013 & 0.015 & -0.819 \\
\hline Sigma-squared & $\sigma^{2}$ & $0.134^{* * *}$ & 0.00004 & 8.667 \\
\hline Gamma [ VAR(u)/VAR(Total)] & $\gamma$ & $0.999^{* * *}$ & & 23563.393 \\
\hline Log-likelihood Value & & -56.11 & & \\
\hline
\end{tabular}

$(* * *, * *, *$ are 1,5 and $10 \%$ significant levels respectively).

\section{Table 5: Frequency Distribution of Technical Efficiency of the Maize Farmers}

\begin{tabular}{cll}
\hline Efficiency class & Number of farmers & Percentage \\
\hline $0-0.2$ & 13 & 5.8 \\
$0.21-0.4$ & 73 & 32.3 \\
$0.41-0.5$ & 38 & 16.8 \\
$0.51-0.6$ & 32 & 14.2 \\
$0.61-0.7$ & 27 & 11.9 \\
$0.71-0.8$ & 15 & 6.6 \\
$0 .-0.981$ & 14 & 6.2 \\
$0.9-1.0$ & 14 & 6.2 \\
Total & 226 & 100.0 \\
\hline
\end{tabular}


Table 6: Inefficiency Model Estimates

\begin{tabular}{lllll}
\hline Variable & Parameters & Coefficient & Standard error & t-value \\
\hline Constant & $\theta_{0}$ & $0.539^{* * *}$ & 0.107 & 5.021 \\
Akuapem North & $\theta_{1}$ & $0.825^{* * *}$ & 0.153 & 5.401 \\
Birem South & $\theta_{2}$ & $0.502^{* *}$ & 0.182 & 2.762 \\
Kwahu North & $\theta_{3}$ & $0.603^{* * *}$ & 0.102 & 5.887 \\
Upper ManyaKrobo & $\theta_{4}$ & 0.185 & 0.191 & 0.968 \\
Farm Experience & $\theta_{5}$ & 0.004 & 0.005 & 0.869 \\
Educational level & $\theta_{6}$ & -0.027 & 0.045 & -0.611 \\
Extension Visit & $\theta_{7}$ & $0.012^{*}$ & 0.007 & 1.749 \\
Household size & $\theta_{8}$ & -0.013 & 0.014 & -0.889 \\
Gender & $\theta_{9}$ & -0.044 & 0.091 & -0.481 \\
FBO Membership & $\theta_{10}$ & $0.477^{* * *}$ & 0.109 & 4.374 \\
Off-maize farm work & $\theta_{11}$ & -0.116 & 0.127 & -0.916 \\
Formal training in maize farming & $\theta_{12}$ & $-0.154^{*}$ & 0.094 & -1.643 \\
Cash credit & $\theta_{13}$ & $-0.429^{* * *}$ & 0.126 & -3.410 \\
In-kind credit & $\theta_{14}$ & $-0.701^{* * *}$ & 0.137 & -5.114 \\
Cash and in-kind credit & $\theta_{15}$ & $-0.605^{* * *}$ & 0.125 & -4.828 \\
Frequency of meeting & $\theta_{16}$ & $-0.237^{*}$ & 0.131 & -1.805 \\
\hline
\end{tabular}

$(* * *, * *, *$ are 1,5 and $10 \%$ significant levels respectively).

Resource Use Efficiency in Maize Production: The Resource Use Efficiency Estimates are presented in Table 7 below. The results reveal that agro-chemicals and hired labour are under-utilized meaning that every $1 \mathrm{GH} \$$ spent on agro-chemicals and hired labour will increase the returns from maize by GH\$2.9 and GH\$1.18 respectively. It is observed that seed, fertilizer and family labour on the other hand are over-utilized as their efficiency ratios are less than one (1). The over-utilization of family labour means that there is surplus of family members who spend too much time in maize production. This unproductive situation could be experienced in places where there are few opportunities for income generating activities outside farming. Hired labour on the other hand, being under-utilized implies that the farmers cannot afford the high cost of obtaining it. The low income status of maize farmers in the country will make it difficult for them to employ the required number of skilled laborers such as farm managers and technicians, and unskilled laborers for their production. The over-usage of chemical fertilizers can lead to soil acidification as a result of a decrease in organic matter in the soil. Hence, crops are unable to extract enough cationic plant nutrients like calcium and phosphorus required for dry matter production. Moreover, the continuous use of chemical fertilizers on soil depletes the soil of essential nutrients. As a result, the maize produced in these soils possesses less vitamin and mineral content (Grant and Rongui, 2008).

The over-utilization of seed in the region may be as a result of type of maize seed the farmers use for their production. The data collected shows that majority of the farmers use their local varieties which have low germination and yielding capabilities since they cannot afford the high price of improved seeds. Therefore, these farmers plant as many as 4 to 6 seeds per hill instead of the recommended 2 to 3 seeds per hill for improved varieties (Addo-Quaye et al., undated). This high seeding rate leads to overcrowding of the seedlings in their respective holes which in turn results in high competition among the growing plants for the same small amount of nutrients and water at their localized area. Thus, the amount of nutrients and water needed by the individual maize plants is reduced giving a resultant reduction in the expected yield of maize. Lastly, under-utilization of agro-chemicals means that the adverse impact of pesticides, insecticides, weedicides and fungicides among others on the soil is minimized to a level that allow the maize plants extract the required amounts of nutrient for their growth and ear formation. The ratio of MVP to MFC is also referred to as complete allocative efficiency (from economic theory) and occurs at the point where everyone cedi spent in getting an additional unit of a resource input into production adds exactly one cedi to the revenue. The results affirm the existing literature that show that farmers in developing countries cannot achieve perfect allocative efficiency because they consider food security goal and avoidance of production risks more important than profit maximization (Okorji, 1983; Awoke, 2002; Amaza and Gwari, 2000). 
Table 7: Marginal Effects of Resources

\begin{tabular}{lllll}
\hline Resource & MPP & MFP & MVP (GHథ) & MVP/MFP \\
\hline Seed & 0.0006 & 50 & 1.00 & 0.02 \\
Fertilizer & 0.065 & 450 & 108.16 & 0.24 \\
Agrochemicals & 0.309 & 175 & 514.18 & 2.94 \\
Family labour & 0.009 & 268.75 & 14.98 & 0.06 \\
Hired labour & 0.143 & 201.56 & 237.95 & 1.18 \\
\hline
\end{tabular}

\section{Conclusion and Policy Recommendations}

The study seeks to identify the main determinants of maize farmers' technical efficiency in the Eastern Region of Ghana. A multi stage random sampling procedure was employed in this study. Purposive sampling technique was employed to select the Eastern Region from the 10 regions of the country as well as the five districts; then simple random sampling procedure was employed to select 63 communities and 226 maize farmers from the communities. A well-structured questionnaire and field observations were employed to collect relevant information from the farmers. Data collected was analyzed using relevant econometric techniques. The results indicate that elasticities of mean output for agrochemicals, other inputs and hired labour inputs are positive while those of seed, fertilizer and family labour are negative. The computed return to scale on the other hand reveals that, on average, the maize farms exhibit decreasing returns to scale. The joint effect of operational and farm-specific factors influence technical efficiency but individual effects of some variables are not significant. Mean technical efficiency level of the farmers is estimated to be $51 \%$, indicating that the possibility of increasing maize production in the region given the current state of technology and inputs level can be achieved in the short run by increasing the technical efficiency level of the farmers by $49 \%$ through the adoption of practices of the best maize farmer. Thus, the realized output can be increased by $49 \%$ without increasing the resource base in the present time. Further, the empirical results from the inefficiency model reveal that extension visit, FBO membership, frequency of meeting by members of FBOs, formal training in maize farming, cash and in-kind credits are the major determinants of the farmers' technical efficiency level. Finally, the resource use efficiency results revealed that agro-chemicals and hired labour are under-utilized whereas seed, fertilizer and family labour are over-utilized by maize farmers in the region.

The study revealed that maize crop farmers are yet to achieve their best, particularly the non-credit users as depicted by their low technical efficiency values. This means that there is more room for improving the technical efficiency of these farmers substantially. Further, the results show that, credit as a single factor cannot produce a higher technical efficiency level among maize crop farmers unless it is accompanied with other complementary factors like access to more agro-chemicals, training on prudent use of credit taken, improved activities of FBO activities and formal training in maize farming among others. Lastly, the results of this study reveal that any expansion in the use of any resources by in-kind credit users, and those farmers who use both cash credit and in-kind credit would result in more than proportionate increase in their output. Thus, in-kind credit users and the farmers using both cash and in-kind credit relatively use resources more efficiently than non-credit users. The study provides the following policy recommendations. There is the need for policy makers to develop formal and/or non-formal (semi-formal) educative training programmes that will raise farmers' capabilities to retrieve and process information about innovative agricultural technology. It is also recommended that maize production should be based on the methods that will utilize more agrochemicals, hired labour, and other inputs. The beneficiaries of any of the forms of credit must be closely monitored and supervised to ensure its efficient utilization. The study provides a suggestion for future research. Further studies should be carried out using panel data to verify the magnitude and main sources of the differences in the effects of determinants of technical efficiency of farmers in the various maize producing districts of the region with a view of designing policies based on each district's peculiarity.

\section{References}

Abdulai, A. \& Tietje, H. (2007). Estimating technical efficiency under unobserved heterogeneity with stochastic frontier models: Application to Northern German Dairy Farms. University of Kiel, Germany. European Review of Agricultural Economics, 34(3), 393-416. 
Addo-Quaye, A. A., Saah, M. K., Tachie-Menson, C. K. B., Adam, I., Tetteh, J. P., Rockson-Akorly, V. K. \& Kitson, J. K. (undated). General Agriculture for Senior High Secondary Schools. Bossah Company Ltd, Ghana, 173178.

Afrait, S. N. (1972). Efficiency Estimation of Production Functions. International Economic Review, 13(3), 56898.

Ahmad-Mohamed, M., Preckel, P. V. \& Ehui, S. (2006). Modelling the Impact of credit on intensification in mixed crop-livestock systems: A Case study from Ethiopia. Poster Paper prepared for presentation at the International Association of Agricultural Economists (IAAE) Conference, Gold Coast, Australia.

Aigner, D. J. \& Chu, S. (1968). Estimating the Industry Production Function. American Economic Review, (58), 826-839.

Aigner, D., Lovell, C. A. K. \& Schmidt, P. (1977). Formulation and Estimation of Stochastic Frontier Production Function Models. Journal of Econometrics, 6(1977) 21-37.

Al-Hassan, R. M. \& Diao, X. (2007). Reducing regional disparities in growth and poverty reduction in Ghana: Policy options and public investment implications. IFPRI discussion paper no. 693. Washington, DC: IFPRI.

Al-Hassan, R., Jatoe, J. D. B. \& Awere, A. D. (2007). Productivity Impact of Improved Maize Varieties in the Eastern Region of Ghana. The IUP Journal of Agricultural Economics, 4(2), 7-22.

Amaza, P. S. \& Gwari, D. M. (2000).The effect of Ecological change in farming Systems in Borno State. Journal of Arid Agriculture, 10, 125-129.

Amaza, P. S., Onu, J. I. \& Okunmadewa, F. Y. (2001). Identification of factors that influence the technical efficiency of cotton farmers in Nigeria. Nigerian Agricultural Development Studies, 2(1), 133-145.

Awoke, M. U. (2002).Resource Use Efficiency in multiple cropping system by smallholder farmers in Ebonyi State in Nigeria. Ph. D Thesis, Department of Agricultural Economics and Extension, ESUT, Enugu.

Barnes, A. (2008). Technical Efficiency Estimates of Scottish Agriculture: A Note. Journal of Agricultural Economics, 59(2), 370-376.

Battese, G. E. \& Coelli, T. J. (1995).A model for Technical Inefficiency Effects in Stochastic Frontier Production Function for Panel Data. Empirical Economics, 20, 325-332.

Binam, J. N., Tonye, J., Wandji N. \& Akoa, M. (2004). Factors Affecting the Technical Efficiency among Smallholder Farmers in the Slash and Burn Agriculture Zone of Cameroon. Food Policy, 29, 531-545.

Carlson, B. (1968). The measurements of efficiency in production. An application to Swedish manufacturing industries. Swedish Journal of Economics, 74, 468-485.

Case, K. E., Fair, R. C. \& Oster, S. M. (2009). Principles of Economics, $9^{\text {th }}$ edition. Pearson Education Inc., Upper Saddle River, New Jersey.

Chirwa, E. W. (2007). Sources of Technical Efficiency among Smallholder Maize Farmers in Southern Malawi. AERC Research Paper, 172.

Coelli, T. J. (1995). Recent Developments in Frontier Modelling and Efficiency Measurement. Australian Journal of Agricultural Economics, 39(3), 219-24.

Coelli, T. J. \& Perelman, S. (1996). A Comparison of Parametric and Non-Parametric Distance Functions: With Application to European Railways. CREPP Discussion Paper, University of Liege, Liege.

Essilfie F. L., Asiamah, M. T. \& Nimoh, F. (2011). Estimation of farm level technical efficiency in small scale maize production in the Mfantseman Municipality in the Central Region of Ghana: A stochastic frontier approach. Journal of Development and Agricultural Economics, 3(14), 645-654.

Fare, R., Grosskopf, S. \& Lovell, C. A. K. (1985).The Measurement of efficiency of production. Kluwer-Nijhoff Publishing, Boston.

Farrell, M. J. (1957). The measurement of productive efficiency. Journal of the Royal Statistic Society, 120, 253281.

Gbigbi, M. T. (2011). Economic Efficiency of Smallholder Sweet Potato Producers in Delta State, Nigeria: A Case Study of Ughelli South Local Government Area. Department of Agricultural Services, Ministry of Agriculture and Natural Resources, Asaba, Delta State, Nigeria.

Ghana Statistical Service. (2012). National Accounts and Economic Indicators Division Accra, Ghana.

Grant, C. \& Ronggui, W. (2008). Enhanced-efficiency fertilizers for use on the Canadian Prairies. Crop Management, 10, 1094.

Greene, W. M. (1980). Maximum Likelihood Estimation of Econometric Frontier Functions. Journal of Econometrics, 13(1), 27-56. 
Hallam, D. \& Machado, F. (1995). Efficiency analysis with panel data: A study of Portuguese Dairy Farms. European Review of Agricultural Economics, 23, 79-93.

Jondrow, J., Lovell, C. A., Materov, V. \& Smith, P. (1982). On the Estimation of Technical Efficiency in the Stochastic Frontier Production Function Model. Journal of Econometrics, 19(3), 233-238.

Kibaara, B. W. (2005). Technical Efficiency in Kenya's Maize Production: An Application of the Stochastic Frontier Approach. Master's Thesis, Colorado State University, USA.

Kolawole, 0. (2010), A Comparative Analysis of Technical and Input-Specific Allocative Efficiencies of Aquaculture Farms in South Western Nigeria, Agriltura Tropica Et Subtropica, 171-175.

Kumbhakar, S. C. \& Lovell, C. A. K. (2000). Stochastic Frontier Analysis. Cambridge University Press, Cambridge, UK. 42-130.

Kwarteng, J. A. \& Towler, M. J. (1995). West African Agriculture: A textbook for Schools and Colleges. Maccmillan Ltd, London, 95-104.

Lee, L. F. \& Tyler, W.G. (1978). The stochastic production function and average efficiency: An empirical analysis. Journal of Econometrics, 7, 385-89.

Meeusen, W. \& Van den Broeck J. (1977). Efficiency estimation from Cobb- Douglas production functions with composed error. International Economic Review, 18, 435-444.

Ministry of Food and Agriculture. (2006). Statistics, Research and Information Directorate (SRID). Accra, Ghana.

Ministry of Food and Agriculture. (2009). Statistics, Research and Information Directorate (SRID). Accra, Ghana.

Ministry of Food and Agriculture. (2010). Statistics, Research and Information Directorate (SRID). Accra, Ghana.

Msuya, E., Hisano, S. \& Nariu, T. (2008). Explaining Productivity Variation among Smallholder Maize Farmers in Tanzania. Graduate School of Economics, Faculty of Economics, Kyoto University, Japan Elibariki.

Ogundari, K. \& Ojo, S. O. (2007). Economic Efficiency of small scale food crop production in Nigeria: A stochastic frontier approach. Journal of Social Sciences (JSS), 14(2), 123-130.

Okorji, E. C. (1983). Consequences on Agricultural Productivity of crops stereotyping along sex line. A case study of four villages inAbakaliki Area of Ebonyi State. M.Sc. Thesis, Department of Agricultural Economics, University of Nigeria, Nsuka.

Olagunju F. I. (2007). Impact of Credit Use on Resource Productivity of Sweet Potatoes Farmers in Osun-State, Nigeria.Department of Agricultural Economics and Extension, LadokeAkintola University of Technology, Nigeria.

Olayide, S. O. \& Heady, E. O. (1982). Introduction to agricultural production economics. Ibadan University Press, Ibadan.

Onoja, A., Ibrahim, M. K. \& Achike, A. I. (2008). Econometric Analysis of Credit and Farm Resource Technical Efficiencies' Determinants in Cassava Farms in Kogi State, Nigeria: A Diagnostic and Stochastic Frontier Approach. Dept. of Agricultural Economics and Extension, Kogi State University, Anyigba, Nigeria.

Onumah, E. E., Brummer, B. \& Horstgen-Schwark, G. (2010). Elements Which Delimitate Technical Efficiency of Fish Farms in Ghana. Department of Agricultural Economics and Rural Development, Georg-August University, Platz der G"ottingerSieben 5, D-37073 G"ottingen, Germany.

Page, J. M. (1980). Technical efficiency and economic performance: Some evidence from Ghana. Oxford Economic Papers, 32, 319-39.

Richmond, J. (1974). Estimating Efficiency of Production. International Economic Review, 15(2), 515-21.

Schmidt, P. (1976). On the Statistical Estimation of Parametric Frontier Production Functions. Review of Economics and Statistics, 58(2), 238-29.

Stevenson, R. E. (1980). Likelihood functions for generalized stochastic frontier estimation. Journal of Econometrics, 13, 57-66.

Tchale, H. \& Sauer, J. (2007). The efficiency of maize farming in Malawi: A bootstrapped translog frontier. Cahiers d'économieetsociologierurales, n82-83.

WABS Consulting Ltd. (2008). Maize Value Chain Study in Ghana: Enhancing Efficiency and Competitiveness. Draft Report, Accra, Ghana.

Waqar, A., Zakir, H., Hazoor, M. S. \& Ijaz, H. (2008).The impact of Agricultural Credit on growth and poverty in Pakistan (Time Series Analysis through Error Correction Model). European Journal of Scientific Research, 23(2), 243-251.

Winsten, C. (1957). Discussion on Farrell's Paper. Journal of Royal Statistical Society, 120, 282-284. 